Obernyik Károly, Schriftsteller. * Kömlőd, Kom. Komorn (Ungarn), 22. 10. 1814; $\dagger$ Pest, 17. 8. 1855. Stud. am evang.-ref. Kollegium in Debreczin, dann an der Univ. Pest Jus (1841 Advokatendiplom) und war später bei der Familie Kölcsey als Erzieher tätig. Bereits von Jugend an literar. interessiert, entwickelte er sich unter dem Einfluß der Werke Hugos und der französ. Romantik zum Schriftsteller und wirkte, bes. auf dem Gebiet des Gesellschaftsdramas, mit stark antiaristokrat. Tendenz. Als Teilnehmer an der Revolution von 1848 mußte er 1849 flüchten, kehrte 1850 nach Pest zurück und wurde zum Notar beim Bühnenkritikerausschuß des Ung. Nationaltheaters bestellt. 1851-55 bekleidete er das Amt eines Prof. am evang.-ref. Kollegium in Kecskemét. O., der Petőfi, Czuczor (s. d.) und Vahot zu seinen Freunden zählte, war auch auf dem Gebiet der Rechtswiss. publizist. tätig.

W.: Ausztria polgári törvénykönyve (Das Bürgerliche Gesetzbuch Österr.), 1853. Dramen: Főúr és pór (Magnat und Bauer), 1844; Örökség (Das Erbe), 1845; Nőtelen férj (Ehemann ohne Gattin), 1846; etc. Obernyik K. szépirodalmi összes munkái (Sämtliche belletrist. Werke K. O.s), red. von J. Ferenczy, 4 Bde., 1878-79.

L.: Egyetemes Philologiai Közlöny, 1889, S. 425ff., 551ff.; M. Faragó, O. K., 1898; I. Luxemburger, O. K. élete és munkái (K. O.s Leben und Werke) 1929-30; J. Ferenczy - J. Danielik, Magyar irók (Ung. Schriftsteller), Bd. 2, 1858; Irodalmi Lex., 1926, 1965; Das geistige Ungarn; M. Életr. Lex.; Pallas; Révai; Szinnyei; Uj Idốk; Wurzbach; $A$ magyar irodalom története (Geschichte der ung. Literatur), red. von I. Sötér, Bd. 4, 1965, S. 677f

\section{(Z. Fallenbüchl)}

Oberparleiter Ignaz, Ps. J. Oberleiter, Schulmann, Musiker und Schriftsteller. * Kaplitz (Kaplice, Böhmen), 3. 4. 1846; $\dagger$ ebenda, 3. 1. 1922. Sohn eines Schuhmachers; stud. ab 1864 an der Lehrerbildungsanstalt in Budweis. $1866 \mathrm{kam}$ er als Hilfslehrer nach Kaplitz und wurde kurze Zeit danach Hauptlehrer an der dortigen Pflichtschule. Ab 1874 unterrichtete O. an der Bürgerschule in Kaplitz, war Chordirigent an der Dekanatskirche und erteilte auch Unterricht in Instrumentalmusik bis zur Konzertreife. Schon in den ersten Jahren seiner Lehrtätigkeit folgte $\mathrm{O}$. seiner Neigung $\mathrm{zu}$ schriftsteller. Arbeit. Wegen dauernder beruf licher Überlastung zog er sich ein Nervenleiden zu und widmete sich nach einem Kuraufenthalt dem Schriftstellerberuf und der Heimatforschung. Aus seinen Schriften sprach der Jugenderzieher, der allerdings sein Bildungsgut ohne didakt. Aufdring- lichkeit vermittelte. Seine Volksstücke zeigten echte dramat. Gestaltung, deren Wirkung auch durch einzelne formale Unzulänglichkeiten nicht beeinträchtigt wird. O. wurde vor allem durch seine Bühnendichtungen bekannt.

W.: Der Findling (Novelle), 1900; Der Berghof (Roman), 1902; Gedenkbuch der Stadt Kaplitz, 1911; Die Moormühle und andere Erz., 1926; Fritz Ernold (Erz.), o. J.; etc. Dramen: Der Zankapfel, 1899; Die Scheinheiligen, 1900; Der Irrlichthof, 1903; Der ungewöhnliche Weg, o. J.

L.: Brümmer; Giebisch-Gugitz; Jaksch; Kosch; Kürschner, 1936; Nagl-Zeidler-Castle, Bd. 4, S. 1351; Partisch, Bd. 1, S. 144f. (V. Hanus)

Oberrauch Heinrich, Forstmann. * Cortina d'Ampezzo (Südtirol), 5. 10. 1880; $\dagger$ Innsbruck, 18. 1. 1948. Sohn eines Forstmannes; stud. 1899-1902 an der Hochschule für Bodenkultur in Wien und war dann Forstpraktikant bei der Wildbachverbauung. Ab 1904 war er im forsttechn. Dienst in ganz Tirol eingesetzt und machte sich bes. um die Gemeindeforstbetriebe des Nonsberges und Ampezzos verdient. O. war 1922/23 Verwalter der Staatsforste in Südtirol (Brixen); 1926-38 und 1943-45 war er im Rahmen der Landesforstinspektion Innsbruck für die Gemeindewaldwirtschaft und das forstliche Schulwesen führend tätig. Breite forstwiss. Interessen und rege ausländ. Kontakte machten ihn zu einer außergewöhnlichen Erscheinung in seinem Fach. In seinem grundlegenden Buch ,Tiroler Wald- und Waidwerk" wurde nur ein Tl. seiner handschriftlichen Ausarbeitungen verwertet.

W.: Tiroler Wald- und Waidwerk, in: SchlernSchriften 88, 1952; mehrere Abhh. in der Z. Der Schlern.

L.: Dolomiten, 1953, n. 52; H. O., Tiroler Wald- und Waidwerk, in: Schlern-Schriften 88, 1952, S. XX Lebenslauf, Landes-Forst-Dion., Innsbruck; Mitt. Familie Oberrauch, Innsbruck.
(F. Huter)

Oberschall Adolf, Jurist. * Rosenberg (Ružomberok, Slowakei), 17. 4. 1839; † ebenda, 9. 9. 1908. Vater des Folgenden; legte nach jurid. Stud. in Preßburg 1862 das Advokatursexamen an der jurid. Fak. der Univ. Pest ab und war 1862-70 Advokat in Pest. Ab 1870 Ersatz-, ab 1872 o. Richter der Pester Gerichtstafel, 1885 Richter an der kgl. Ung. Kurie. 1886 Präs. der Gerichtstafel in Neumarkt (Siebenbürgen), ab 1891 Präs. der Gerichtstafel in Kaschau. 1894 Senatspräs. an der kgl. Ung. Kurie, ab 1901 Präs. der Gerichtstafel in Budapest. 1903 Geh.Rat; ab 1903 Vizepräs., 1906-08 Präs. der kgl. Ung. Kurie, des Obersten Gerichtshofes Un- 